\title{
EDUCAÇÃO PERMANENTE NAS ESTRATÉGIAS MOTIVACIONAIS NO AMBIENTE DE TRABALHO E NA QUALIDADE DO SERVIÇO DE SAÚDE
}

\author{
Wesdisley Magalhães de França ${ }^{1}$ \\ Creusa Alves Vieira ${ }^{2}$ \\ Cristiano do Nascimento Siqueira ${ }^{3}$
}

\begin{abstract}
A educação permanente tem a capacidade proporcionar aprendizado aos profissionais, esse aprendizado tem uma relevância ainda maior nos serviços de saúde, pois é lá onde muitas vezes são vivenciadas situações de vida ou morte. Há a necessidade em salientar que a motivação dos profissionais também é parte essencial para o bom funcionamento do serviço de saúde e que a educação permanente em saúde além de realizar a melhoria organizacional e administrativa é ainda capaz de auxiliar na promoção da motivação nos trabalhadores. Porém, essas melhorias não são feitas com facilidade, por conta do contexto psicossocial e cultural dos trabalhadores envolvidos. A partir da análise sobre a importância da educação permanente como estratégia motivacional no ambiente de trabalho e da reflexão da motivação dos trabalhadores no atendimento do serviço de saúde a pessoa hospitalizada, viu-se a necessidade da realização deste artigo. Por esse motivo o artigo tem objetivo de discutir sobre educação permanente em saúde e os pontos que levam à motivação profissional e, apresentar alguns dados sobre o contexto em que os profissionais estão inseridos e sobre sua crença acerca dos fatores motivacionais. Os dados foram colhidos através de entrevistas, que foram realizadas com 45 profissionais de saúde, sendo em sua maioria do sexo feminino, com idade entre 25 e 65 anos. Um dado que deve ser ressaltado foi referente a opinião acerca dos fatores motivadores onde foram estabelecidos três fatores principais na motivação: a remuneração, a chefia e próprio profissional e outro é a quantidade de profissionais que não sentem sua chefia os estimular o que denota a falta de participação dos cargos de liderança na motivação de sua equipe.
\end{abstract}

Palavras-Chaves: Educação permanente. Estratégias motivacionais. Ambiente de trabalho. Qualidade do serviço. Serviço de saúde.

1.Wesdisley Magalhães de França, Graduada em enfermagem pela Centro Universitário Maurício de Nassau (UNINASSAU), mestre em educação pela Facultad Interamericana de Ciencias Sociales (FICS)- Email: lylasol@gmail.com. 2 Creusa Alves Vieira: Graduada em enfermagem pela Centro Universitário Maurício de Nassau (UNINASSAU), mestre em educação pela Facultad Interamericana de Ciencias Sociales (FICS)-Email: creusaavieira@gmail.com 3. Orientador: Cristiano do Nascimento Siqueira, Graduado em enfermagem pela Centro Universitário Maurício de Nassau (UNINASSAU), mestre em educação pela Facultad Interamericana de Ciencias Sociales (FICS)- Email: lylasol@gmail.com. 


\section{INTRODUÇÃO}

A educação permanente em ambiente de serviços de saúde é uma forma de aprendizagem no trabalho, essa modalidade de intervenção é de enorme potencial que alcança diversos graus de visibilidade e prioridade em função das concepções e enfoques administrativos e organizacionais atual.

Segundo Almeida (2016), com base na origem do sistema único de saúde (SUS) é notório a necessidade de alterações na grade curricular dos profissionais de saúde. Esses profissionais de saúde em sua maioria são formados com alto conhecimento técnico, contudo, muitos deles são incapazes de entender as diversidades culturais dos seres humanos (ALMEIDA, 2016).

O desenvolvimento progressivo da qualidade do trabalho tem como base a educação permanente que não termina com a simples estratégia. A razão é a mesma que gerou as dificuldades: trata-se de processos sociais complexos, que se revertem aos níveis prévios de desempenho, ainda que seja introduzido alterações efetivas, a menos que se tomem medidas para incrementar o nível da melhoria alcançada.

Por outro lado, é de extrema importância que os trabalhadores da saúde apresentem estimulados no trabalho para assim prestar melhor qualidade dos serviços por eles prestados.

A palavra motivação tem sua derivação do latim, tem seu significado movimentar, ou seja, é o processo pelo qual um conjunto de argumentação que induzem, incentivam, estimulam e promovem ações e/ou comportamentos humano. Portanto, podemos definir a motivação como a causa que leva a ação para determinados fins (FRANÇA, 2019).

É importante enfatizar, que dentro de uma organização é primordial que os funcionários estejam motivados, pois são essas pessoas que são responsáveis pela produtividade. A motivação se traduz em força que ajuda o funcionário lutar por suas conquistas. Os indivíduos não esperam somente prêmios financeiros como maiores salários ou gratificações, mas anseiam também por prêmios intangíveis como elogios, reconhecimento ou poder, como também necessitam estar motivados. 
O mundo dos negócios está cada vez mais competitivo e as empresas necessitam de funcionários motivados para serem capazes de concorrer, pois um empregado desmotivado não se importará com os prejuízos atribuídos à empresa.

Este trabalho, objetiva mostrar formas estratégicas para que se alcance a motivação no ambiente organizacional, sabendo-se que a motivação é um processo e não um evento isolado e que muitas vezes a falta de motivação encontra-se na estrutura organizacional ou na deficiência da relação entre o líder e seu seguidor, pois como se sabe a motivação acelera ou desacelera o desempenho profissional.

A presente propostas teórica e metodológica contidas neste artigo objetivou oferecer métodos para superação dos problemas manifestados no trabalho e da atenção que é oferecida nos serviços de saúde, considerando as dificuldades que essa área atravessa e aproveitando todos os momentos que contribuam para reversão dessas situações.

\section{DESENVOLVIMENTO}

\subsection{Educação permanente}

A produção do conhecimento permanente em saúde é compreendida como ferramenta de grande relevância nas estratégias e nos processos de transformação das instituições, sendo fundamentada pelos conceitos aprendizagem e problematização. O processo de ensino e aprendizagem acontece mediante a reflexão do contexto social, vivida habitualmente, tendo o empregado a capacidade de imaginar condutas inspiradoras que permitam traçar caminhos para contornar os problemas vivenciados na coletividade ou individualmente (PEREIRA, 2018).

Essa estratégia educativa, realizada no espaço de trabalho/produção/educação em saúde, apresenta-se como de grande contribuição para a melhoria da qualidade dos serviços e das condições de trabalho ao incorporar os princípios da problematização, a contextualização da realidade, as pedagogias inovadoras e 0 pensamento reflexivo (PEREIRA, 2018, p. 02) 


\subsection{As instituições de saúde}

Segundo alguns autores da área que reproduzem a ideia da composição das instituições de saúde em geral por (hospital, ambulatório, centro de saúde e consultório) sendo inseridas no contexto da construção social, como causalidade do processo histórico de gestão em grupo, por vários fatores como a cultura, os valores, as capacidades e saber, que se apresentam, e são reproduzidas por ações de movimento perene. É de extrema importância ressaltar que certos modelos de entendimento acerca da gerência dos serviços de saúde que enfocam a percepção da parte física do estabelecimento e deixam a noção sociável a parte.

Ao aspirar a fundamentação de um projeto de educação permanente é imprescindível compreender a instituição de saúde como um local de trabalho e educação continuada, onde é encontrada uma soma variada de relacionamentos, ocorrências e desenvolvimento de cunho cultural, econômico, técnico e em especial ideológico. A partir desta visão é de grande relevância a observação de componentes institucionais, para que haja o entendimento das mudanças, pois eles se apresentam como agentes das áreas de atuação na realização da práxis, que são: o processo de trabalho realizado, a estrutura hierárquica e os costumes da instituição.

\subsection{Saúde Mental e Trabalho}

A prática de trabalho atual, causa efeitos reversos a saúde dos trabalhadores, de maneira biopsicossocial. As variadas transformações advindas da globalização, das utilizações de novas tecnologias, que se atualizam a todo momento e pela organização de novas gestões implicam de forma direta para o déficit na vitalidade dos trabalhadores, causando um grande impacto no seu processo de trabalho, seja individual ou coletivamente (SILVA, 2016).

A partir da visão de Masumoto (2015, p.02) entende que "O trabalho tende a ocupar uma dimensão central na vida de um sujeito", porém, existem mais pontos a serem considerados, tal qual a família ou doença. Esses tópicos têm a capacidade de ser agentes do sofrimento mental especialmente quando estas condições interatuam entre elas, de uma forma que se modifica a partir da individualidade do ser 
humano, levando em conta a história pregressa de sua vida, e o valor pessoal privativo que é atribuído ao trabalho.

Ao depender do contexto, o trabalho consegue beneficiar ou não a saúde do trabalhador ou o grupo de trabalhadores, afetando os aspectos psicossociais e levando a problemas dessa magnitude, o que atinge até mesmo o âmbito biológico, causando doenças de cunho psicossomático e psiquiátrico. Contudo, a realização dessa ligação não é tão fácil, levando em conta que o reconhecimento clínico dos distúrbios psíquicos conectados ao trabalho é dificultado pela amplitude das formas de adoecimento e de manifestações em que o sofrimento se apresenta (MASUMOTO, 2015).

O trabalho não deve ser visto como algo negativo para vida do trabalhador, muito pelo contrário, deve ser algo prazeroso que além da parte financeira tenha um ganho psicológico nas execuções do mesmo.

\subsection{Motivação no trabalho}

A palavra motivação é derivada do latim, que descreve "movimento", ou seja, o que move, motiva, ou impulsiona a pessoa a buscar novas conquistas, sucessos e realizações pessoais.

Segundo Leite (2016, p.02), "o grau de satisfação e de motivação pode afetar a estabilidade interna de todo um sistema". Conforme alguns autores, entende-se que a desmotivação de um funcionário atua diretamente na conjuntura organizacional, fazendo com que essa desmotivação se sobressaia a ela, gerando desequilíbrio no serviço e em outros empregados de modo individual. Ainda de acordo com a autora, o entendimento de motivação, dar-se por: "estado que o colaborador apresenta vontade de ser produtivo em seu trabalho". A motivação tem apresentado um importante papel na produtividade que é conceituado pelo "posto que o colaborador que se sente motivado para realizar suas tarefas proporciona melhores resultados para a organização", fato frequente e de extrema relevância que hoje é requerido no campo dos negócios que é um mundo onde a competição é requisitada cada vez mais ao passar dos anos (LEITE, 2016). 
Considerando que a motivação possui várias vertentes, destaca-se que "a compreensão de motivação é tudo aquilo que impulsiona uma pessoa a adotar um comportamento específico". Da mesma forma, é falado que ela traça metas estabelecidas nas quais existe demanda energética, e tem possibilidade de apresentar-se em estado de receios ou desejos (LEITE, 2016, p.02).

De acordo com França (2019, p. 30), a teoria da expectativa pode ser associada a hierarquia de necessidades de Maslow, que institui que" o indivíduo move-se em direção a níveis cada vez mais superiores de realização, contudo, estacionara no limite ditado por suas expectativas de sucesso". Outro tópico relevante que deve ser levando em consideração é a ideia que o indivíduo tem sobre justiça, a crença de que seus esforços para produzir o comportamento necessário, receberão justa recompensa. A Justiça tem seu conceito diretamente relacionado com equidade, como exemplo a ser citado, a proposta da remuneração baseado apenas no emprego das pessoas e não na produtividade que cada profissional apresenta, mesmo a produtividade sendo fundamental para a melhor qualidade do serviço e proporcionando uma maior eficácia na visão do cliente.

A injustiça traz desmotivação, e essa desmotivação acaba enfraquecendo a produção e consequentemente na colaboração entre os trabalhadores.

Segundo França (2019, p. 31) "A motivação é uma força interior propulsora, de importância decisiva no desenvolvimento do ser humano". Por isso é necessária a formação dessa força nos trabalhadores, o que pode ser feito através da aprendizagem, pois a aprendizagem deve ser um processo ativo.

A motivação é originada na ambição da satisfação de desejos e necessidades. Por ser um animal racional e social, o ser humano tem necessidade, inegável, em relacionar-se com os próximos viventes em um ambiente comum. Existem fatores internos e externos para ativação da motivação. A tendência à integração de um coletivo de pessoas é o agente interno principal para a ativação da motivação em várias de suas ações.

Os fatores externos são representados pelo ambiente que frequentamos e suas individualidades, se esse ambiente proporciona ações de interesse do educando a motivação será atingida de maneira mais íntegra. Não é um 
tratamento e sim uma construção de competências. O aluno não pode depender do professor para o aprendizado de um método funcional, ele deve estar motivado a esse aprendizado, pois ninguém é capaz de causar motivação em ninguém, a própria pessoa deve ser sentir motivado a sua vontade. É comum atribuição a outras pessoas de objetivos próprios, e isso é de fácil percepção quando ocorre.

Enfocando a motivação a função do administrador é descrita atualmente como sendo a criação de circunstância de trabalho favoráveis à motivação, o que é uma tarefa complexa por ter que lidar com ações humanas. O estudo do comportamento humano, torna-se necessário e não é feito com facilidade pois ele é individual e está em variação constante. No entanto é possível observar vários pontos que as pessoas em sua maioria reagem de forma favorável. Para a grande parcela da população, uma atividade que é melhor remunerada as motiva de maneira mais positiva. A criação de desafio também é um bom incentivo. Sobrepujar metas ou superar departamentos que não o seu, dentro da empresa é um grande estímulo. Outra questão importante é o ambiente de trabalho, um ambiente favorável e com boas instalações, retiram preocupações não relacionadas ao exercício de trabalho.

Compelir as pessoas ao trabalho é um dos temas básicos para uma empresa. atualmente isso é uma tarefa árdua por conta da não obtenção de satisfação em seus respectivos trabalhos. Muitas vezes as pessoas que trabalham em grandes empresas, recebem ordens que nem sempre são aprovadas, fazendo com que não aconteça a participação dos funcionários deixando-os desmotivados. São pontos a serem realizados para uma melhor motivação:

- Identificar as necessidades e anseios das pessoas;

- Buscar o trabalho que mais atrai a pessoa;

- Reconhecer o bom desempenho;

- Facilitar o desenvolvimento da pessoa;

- Projetar o trabalho de modo a torná-lo atraente;

- Adotar um sistema de recompensas ligado ao desempenho;

- Aperfeiçoar continuamente as práticas gerenciais. 
As Pessoas obtêm motivação a partir de dois fatores, que podem ser os de cunho intrínseco ou extrínseco. O intrínseco vem a partir das concepções individuais de cada pessoa, já o extrínseco é quando a motivação é gerada a partir de fatores externos, como o seu ambiente de trabalho. Para além desses fatores a motivação também é classificada como sendo direta, que ocorre quando o objetivo é a necessidade principal, ou indireta, ou instrumental, que acontece quando a motivação para determinado objeto dar-se como um instrumento para atingir um objetivo maior (FRANÇA,2019).

\title{
2.5 Motivação e sua influência no âmbito organizacional
}

A motivação menciona vários fatores que auxiliam no direcionamento e no comportamento do ser humano, possui características próprias que são exteriorizadas.

A motivação refere-se "aos fatores que provocam, canalizam e sustentam o comportamento de um indivíduo", tem caráter interno, ou seja, de dentro para fora. Tal motivação tem grande influência para motivar a pessoa, auxiliando para melhor produtividade e eficácia em seu ambiente de trabalho (VILELA, 2010, p.16)

Segundo Blanchard (2016, p.16)

\begin{abstract}
Motivação é a disposição para fazer alguma coisa e está condicionada pela capacidade de essa ação satisfazer uma necessidade do indivíduo. Uma necessidade não satisfeita gera tensão, o que estimula a vontade do indivíduo. Essa vontade desencadeia uma busca de metas específicas que, uma vez alcançadas, terão como consequências a satisfação da necessidade e a redução da tensão. Assim, quando os funcionários trabalham com afinco em alguma atividade, pode-se concluir que estão sendo movidos pelo desejo de atingir uma meta que valorizam.
\end{abstract}

Dessa forma, fica latente a ideia de que motivação é um estado de espírito que impulsiona o indivíduo a objetivos, para contentamento das carências pessoais. Motivação seria, então, o que leva o indivíduo a mover-se do estado de repouso à ação.

Motivação num ambiente de trabalho é o processo pelo qual o comportamento é mobilizado e sustentado no interesse da realização das metas 
organizacionais. Uma pessoa está motivada quando ela realmente despende esforço para alcançar a meta (LUIZ, 2019).

Segundo Luiz (2019, p.33), diz que assegura que: "o ambiente de trabalho produz satisfação com próprio ambiente".

O autor se refere aos fatores higiênicos ou extrínsecos citados por Herzberg, que são os benefícios sociais, salários, tipos de chefia ou supervisão, condições físicas e ambientais de trabalho, diretrizes e políticas da instituição, a condição em que o relacionamento empregado-empregador se apresenta, normas internas, entre outras coisas.

Atualmente as organizações estão investindo mais nessa ferramenta que é a "motivação", utilizando estratégias competentes, enfocando o capital humano como peça central no desenvolvimento da cultura organizacional.

A primeira explicação importante sobre motivação é representada pela teoria proposta por de Abraham Maslow:

a chamada Hierarquia das Necessidades Humanas, em que as necessidades são visualizadas em forma de uma pirâmide em níveis de importância e influência, onde cada vez que satisfeita as necessidades de um desses níveis surge a seguinte para servir de centro da organização do comportamento. Em sua concepção, quando uma necessidade é satisfeita ela deixa de ser motivadora de comportamento, passa a ser motivada pela ordem seguinte das necessidades, portanto para motivar um indivíduo é preciso saber em que ponto ele se situa na pirâmide, é esse o aspecto mais criticado visto que os indivíduos podem sentir diversas necessidades ao mesmo tempo ou até mesmo abrir mão de uma necessidade de nível inferior por outra de nível mais elevado (LUIZ, 2019, p.31).

De acordo com a teoria: "dificilmente atinge-se o topo da pirâmide, pois sempre haverá novos objetivos e sonhos". Sendo essa teoria, uma das mais conhecidas no campo da motivação humana e segundo a qual o comportamento tem sua motivação baseada conforme a condição de carência que leva as pessoas a busca incansável dessa satisfação (FRANÇA, 2019, p.18).

A representação a seguir é uma demonstração da Hierarquia das Necessidades Humanas, elaborada por Abraham Maslow: 


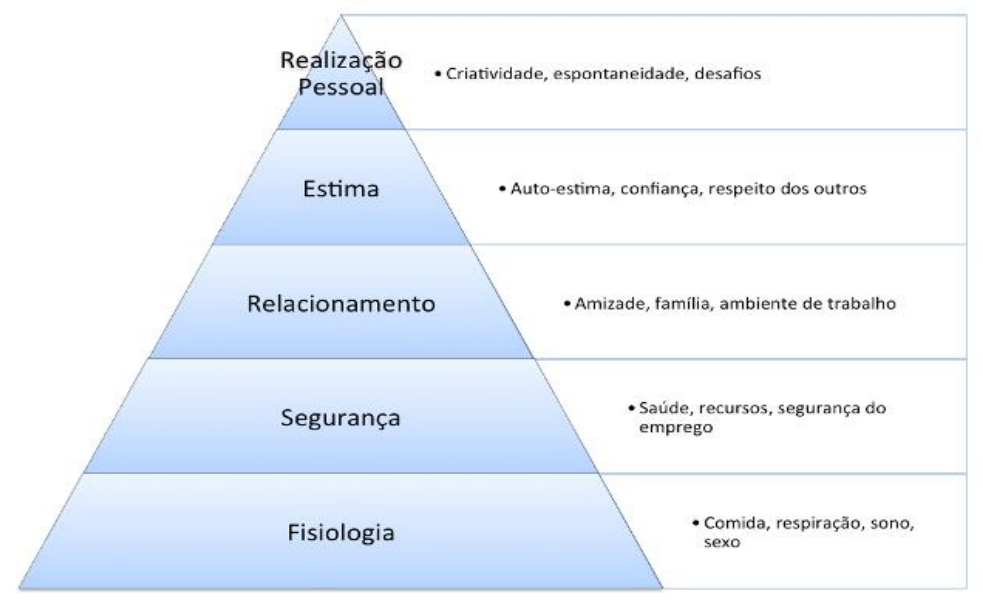

Figura 1: Pirâmide da Teoria da hierarquia das necessidades humanas de Abraham Maslow Fonte: MIRANDA (2017)

Maslow teve sua teoria aprovada por vários psicólogos, porém sem confirmação, pois não foram realizadas muitas pesquisas com o intuito de verificar-la, assim Miranda (2017, p.19) define: "é comprovadamente fácil interpretar situações com o seu modelo, mas é algo mais espinhoso testar realmente sua realidade".

Conforme Miranda (2017, p.19):

Então, nesse sentido e influenciado por Maslow, Frederick Herzberg desenvolveu a teoria dos dois fatores para explicar o comportamento das pessoas em situação de trabalho, conhecido como Teoria Motivação-Higiene. Segundo Herzberg, existem dois fatores que orientam o comportamento das pessoas. Os fatores higiênicos ou extrínsecos e os fatores motivacionais ou intrínsecos. O primeiro está relacionado com o ambiente que rodeia o indivíduo, envolvem as condições físicas de trabalho e estão fora do controle das pessoas, eles apenas evitam a insatisfação no trabalho, mas isoladamente não gera motivação, são destinados simplesmente como forma preventiva de evitar insatisfação e manter o equilíbrio do ambiente, pois eles criam um clima psicológico e material saudável.

Ainda segundo Miranda (2017, p. 20) diz que o ponto principal é a teoria que "satisfação e a insatisfação não são extremos opostos de um mesmo continum", porém são processos distintos, inspirados em fatores variados, conforme mostra no quadro 1 , a seguir que esclarece o oposto de satisfação não é insatisfação: 


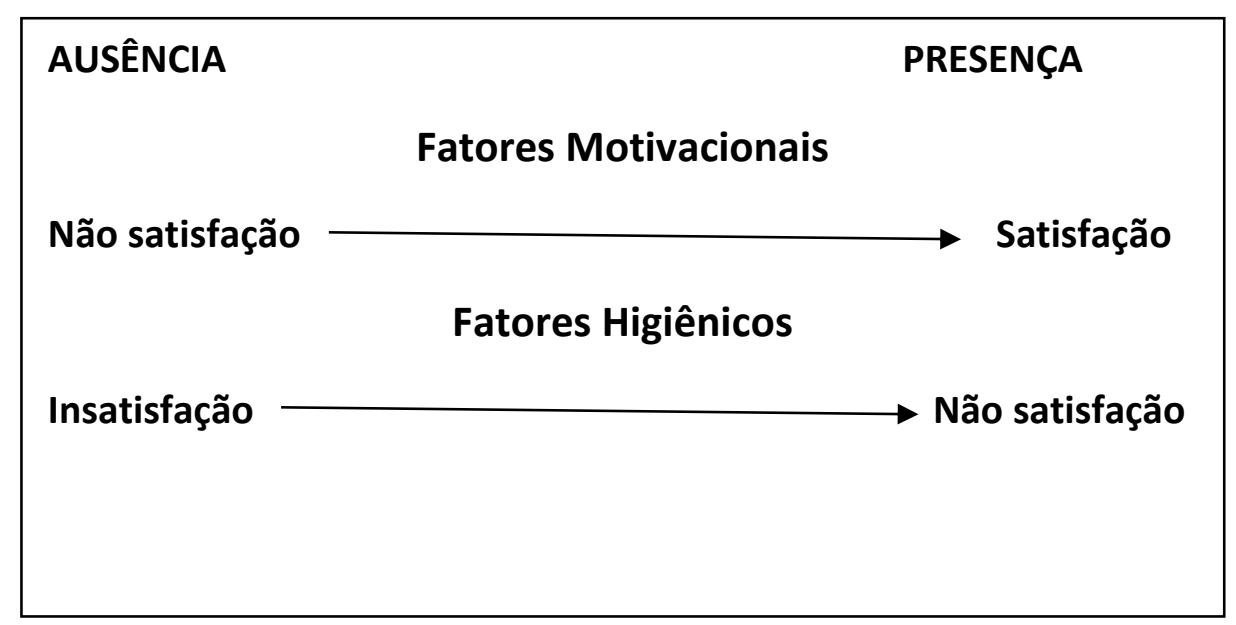

Quadro 1: Fatores de satisfação no trabalho Fonte: MIRANDA (2017)

Segundo Machado (2017), o papel do líder é atuar de forma que o potencial de seus colaboradores se torne ação, em prol dos objetivos organizacionais. Porém, para tal, faz-se necessário conhecer aspectos gerais do ser humano, em suas várias dimensões, e aspectos particulares de cada indivíduo, no tocante a sua singularidade, a sua subjetividade.

É evidente o papel motivacional do gerente para com o empregado. Isso é elucidado a partir da observação da variedade de necessidades que os empregados apresentam e, portanto, não devem ser tratados da mesma forma. Devem ser estabelecidas metas e dados bem como os respectivos feedbacks sobre seu progresso. A participação dos empregados, nas decisões que os interessa, é de extrema relevância, isso os motiva na melhoria de produtividade, aumenta o comprometimento com as metas desejadas e atua diretamentamente na satisfação com seu trabalho (MACHADO, 2017).

\subsection{Satisfação no trabalho como sinônimo de motivação}

A confusão entre os termos "motivação" e "satisfação" tem sido efeito causador de falhas na fomentação de hipóteses e na seleção de instrumentos de pesquisas, especialmente naquelas destinadas a correlacionar satisfação no trabalho com produtividade (MARTINEZ \& PARAGUAY, 2015). A diferença entre motivação e satisfação é claramente assinalada por Martinez \& Paraguay (2015), 
ao explicitar que motivação manifesta a tensão gerada por uma necessidade e satisfação expressa a sensação de atendimento da necessidade.

\subsection{Motivação no trabalho e suas consequências}

O comportamento, a motivação e o desempenho apresentam uma relação que é estabelecida tanto cientificamente quanto de forma empírica. A visão do comportamento percebida através da sua causalidade como sendo por parte das metas pessoais e individuais. Em relação a motivação, muitos autores a referenciam como um seguimento psicológico que tem conexão com o impulso, com a perseverança na manutenção de alguns comportamentos no intuito de chegar a um objetivo.

Associando a motivação com trabalho, observa-se a manifestação da mesma com a orientação do funcionário com a intenção de fazê-lo desempenhar suas tarefas com precisão e presteza até alcançar o resultado almejado. De maneira geral são citados três partes para a motivação, que são: Geralmente, "impulso, a direção e a persistência do comportamento" (FRANÇA, 2019, p.34).

O assunto motivação recebe grande atenção internacional, isso ocorre por conta da sua relação com a produtividade no trabalho, seja individual ou da organização como um todo. A grande dificuldade sobre motivação é quando há conflito de interesses entre a empresa e empregado, pois deve sempre haver uma parceria entres as partes, onde um apresenta ao outro, suas demandas e exigências.

No tocante a organização, há demandas que são nítidas e muito precisas relativas à atuação do empregado e as normas da organização. Referente ao desempenho, a instituição demanda a execução de deveres estabelecidos previamente e bem determinados, com exigência de um padrão de qualidade e quantidade de trabalho, dentro de um período de tempo. Todas essas requisições fazem parte da função do empregado, regidas por um contrato de trabalho. A empresa deve fornecer aos seus empregados os materiais necessários para a realização de suas demandas.

As tarefas da organização também são relativas à implementação das regras de comportamento que tem função de regular a convivência entre os 
membros, a realização do trabalho e o curso de projetos e processos relativos à organização. Para Além, existem exigências e possibilidades almejadas pela empresa em alusivo a comportamentos que devem ser espontaneamente apresentados pelo funcionário, como o altruísmo para com o crescimento da empresa que tem uma importância fundamental (FRANÇA,2019).

De maneira geral, diz-se que são ações "extra papel", que são executadas de forma espontâneas e são benéficas para o sistema organizacional. Várias condutas desse modelo têm sido analisadas, tais como: cidadania organizacional, espontaneidade organizacional e civismo organizacional. Essas condutas têm dois atributos em comum, que são a espontaneidade e são benéficos para a instituição (FRANÇA,2019).

Segundo França (2019), as organizações que são fundamentadas apenas na função prescrita, acabam tendo uma base frágil. As condutas espontâneas são imprescindíveis para a sequência das tarefas de cunho organizacional que não se apresentam de maneira formal nas funções da empresa.

As exigências para o ambiente de trabalho requeridas pelo empregado referem-se de maneira geral a ter um tratamento de respeito, humanizado e ter oportunidades dentro da empresa de obter a realização de seus objetivos e necessidades, por meio do seu trabalho. A partir da entrada do indivíduo numa instituição, com a intenção de realizar um trabalho, a base do seu pensamento é saldar suas necessidades e não aumentar o lucro da empresa. Caso o trabalho não proporcione ferramentas para a satisfação dos seus desejos ele se sentirá explorado e não terá uma relação de parceria. O empregado devota seus conhecimentos e habilidades para o trabalho, além de sua experiência e por consequência sua motivação. Da mesma forma há a carga negativa, que são as limitações relacionadas a sua habilidade e conhecimento precisos na realização das suas tarefas.

As consequências benéficas advindas do equilíbrio na dinâmica empresaempregado, traz vantagens mútuas para os dois. Essas vantagens são representadas pela qualidade do trabalho realizado pelo funcionário. As consequências para ele situam-se principalmente no nível da realização pessoal, autoestima e bem estar. 
Ainda segunda França (2019), funcionários insatisfeitos não dedicam plenamente suas habilidades, conhecimentos e principalmente se esforço no trabalho, logo é indispensável a valorização dos trabalhadores, por parte da organização a que são empregados para que haja o destaque na empresa no mercado.

\subsection{Teorias da motivação e planos de motivacionais}

Segundo alguns autores estudiosos da área, dizem que são várias hipóteses vêm sendo pensadas para obter a explicação da motivação trabalhista. A princípio essas explicações vieram de forma simples, onde eram fundamentadas em apenas uma dimensão, de forma que a relação entre o empregado e seu emprego não era considerada. De acordo com a teoria da administração científica de Taylor: "considerava-se que o salário era o motivador fundamental e que ele era suficiente para obter o desempenho esperado do trabalhador" (FRANÇA, 2019, p.36).

Partindo do molde econômico humano, foi criada uma hipótese sobre a motivação do trabalho. Mais tarde, ocorreu a criação de várias outras que apresentaram mais complexidade e abordando o contexto psico-sociocultural.

\subsection{Fatores que causam motivação}

Desta forma, se a competência da cultura organizacional for confiável, esse ciclo de influências ampliará comportamentos construtivos, gerando mais produtividade com qualidade de vida. Mas, se a cultura organizacional não for virtuosa esse ciclo arrastará a empresa para comportamentos cada vez destrutivos, defasando a produtividade, causando danos às pessoas e os seus relacionamentos (FRANÇA, 2019). 
O clima organizacional é a qualidade do ambiente que é percebida ou experimentada pelos participantes da empresa e que influencia o seu comportamento. É aquela atmosfera psicológica que todos nós percebemos quando entramos num determinado ambiente e que nos faz sentir mais ou menos à vontade para ali permanecer, interagir, realizar (FRANÇA, 2019, p.52).

Portanto, é de vital conhecimento, os determinados fatores que dificultam a manutenção de um clima organizacional produtivo de pretendemos intervir de forma significativa.

Frederick Herzberg a partir da obra de Maslow, criou o "princípio dos dois fatores" que explica a conduta das pessoas que o comportamento das pessoas no ambiente de trabalho, denominado como "Teoria Motivação-Higiene". A teoria dos dois fatores propõe que:

Segundo Herzberg existem dois fatores que orientam o comportamento das pessoas: Os fatores higiênicos ou extrínsecos e os fatores motivacionais ou intrínsecos. O primeiro está relacionado com o ambiente que rodeia o indivíduo, envolvem as condições físicas de trabalho e estão fora do controle das pessoas, eles apenas evitam a insatisfação no trabalho, mas isoladamente não geram motivação (MIRANDA, 2019, p 20).

Esses fatores são destinados simplesmente como forma preventiva de evitar insatisfação e manter equilíbrio do ambiente, pois eles criam um clima psicológico e material saudável.

Na opinião de Maximiano (FRANÇA, 2019). Os fatores motivacionais ou intrínsecos estão relacionados com o conteúdo do cargo, ou seja, com aquilo que o indivíduo faz, portanto estão sobre o controle do indivíduo. São aqueles responsáveis diretamente pela concepção da satisfação, há a dependência de sua atuação, se agem de forma excelente ou precária. Envolvem evolução pessoal, autorrealização, reconhecimento profissional, etc. Assim, de acordo com essa teoria não basta boas condições de trabalho para que haja uma condição motivadora, para isto é preciso que o indivíduo esteja satisfeito com o seu trabalho (FRANÇA, 2019). 


\subsection{Liderança e motivação}

Diz-se que atualmente a liderança tem valor inestimável por ser uma ferramenta para a conquista de metas e objetivos pré-estabelecidos, por isso faz-se necessário a presença de bons líderes na organização do trabalho. Liderança, é um ponto que tem sido cada vez mais abordado e vem se atualizado cada vez mais e são escassas as empresas que não tem preocupação com a presença e atuação de líderes. Por isso, há a maior busca de pessoas qualificadas para a gestão organizacional de um trabalho e seus envolvidos.

\footnotetext{
Segundo França (2019, p. 53), diz que os líderes assumem o controle, fazem com que as coisas aconteçam, sonham e depois traduzem esses sonhos em realidade. Os líderes atraem o compromisso voluntário dos seguidores, energizando-os, e transformam as empresas em novas entidades, com maior potencial de sobrevivência, crescimento e excelência.
}

Uma liderança eficiente e eficaz possibilita a maximização do auxílio de uma empresa no bem estar dos seus funcionários e da sociedade em que está inserida. Os gerentes são requisitados por habilidades relacionadas à solução de problemas, já no caso dos líderes, eles são importantes por serem pessoas encubidas e eficientes na projeção e construção das determinadas organizações (FRANÇA, 2019).

Ainda segundo França (2019), as mudanças atuais, constantes e frenéticas do mundo das corporações ínsita esforços enormes das instituições nacionais e internacionais para adaptação das capacidades humanas as carências da competição internacional, o que incide na qualidade e controle do uso de recursos, trazendo eficácia na administração de recursos e no serviço proposto ao cliente.

Porém ainda há empresas que mesmo se preocupando com as "políticas de gerência de pessoas, não atingem o objetivo de desenvolvimento e estimulação da "competência humana" eficientemente e com eficácia para competirem no mercado. Essas circunstâncias levam ao entendimento de que a gestão humana e das habilidades das mesmas não é conectada a utilização dos meios de administração e gestão, entretanto pela cooperação e compreensão 
dos líderes acerca da sua função verdadeira no gerenciamento dos recursos humanos. (FRANÇA, 2019).

No intuito de preparação de forma distinta, das organizações de preparar as organizações para um mundo que é também distinto faz-se necessário o investimento de dinheiro e tempo na construção de habilidades de liderança. As organizações precisam de pessoas capazes de liderar de forma plena para $p$ desenvolvimento de recursos e serviços. (FRANÇA, 2019).

Maxwell cita que:

\begin{abstract}
A responsabilidade pelo desenvolvimento das pessoas recai sobre 0 líder. E isso significa mais do que apenas ajudá-las a adquirir habilidades profissionais. Os melhores líderes ajudam os liderados não só em relação à carreira, mas também em relação à vida pessoal. Eles os ajudam a se tornar pessoas melhores, e não apenas bons profissionais. Os líderes potencializam os liderados. $E$ isso é muito importante, pois promover o crescimento das pessoas gera crescimento para a organização. (MAXWELL, 2008, p.96).
\end{abstract}

Uma etapa crítica para o progresso das competências de liderança, passa a ser a implementação de metas. pois há função de espelho guia e motivador de uma equipe, pôr o líder ser um exemplo que deve ser seguido. O líder acaba sendo o responsável pelos possíveis erros de gestão, como também dos acertos e conquistas. A forma como o líder se porta é capaz de mudar a forma de trabalho cotidiana do empregado, pois suas ações são decisivas. De maneira geral a conduta dos liderados, demostra a forma de liderança exercida pelo líder.

França (2019, p.54) conceitua liderança pela "capacidade de exercer influência sobre as pessoas". De acordo com ele "liderança é a arte de comandar pessoas, atrair seguidores, servir e influenciar de forma positiva para se alcançar um objetivo em comum".

O desafio de ser líder é enorme, pois exige dele muita competência, dedicação, perseverança e paciência, ele precisa estar sempre pronto, ter humildade e comprometimento com o serviço e seus liderados e outras virtudes necessárias ao Ser Humano.

Chiavenato refere que:

A liderança é necessária em todos os tipos de organização humana, seja nas empresas, seja em cada um de seus departamentos. Ela é essencial em todas as funções da administração: o administrador precisa conhecer a natureza humana e saber conduzir as pessoas, isto é, liderar. (CHIAVENATO, 2006, p.18-19). 


\subsection{Estilos}

O estilo autocrático é mais voltado para o líder, e geralmente é adotado pelos homens, existe um líder que é responsável pela tomada de decisões que são impostas, tem a característica da tentativa de resolução de problemas de forma individual, com quase nenhuma participação dos liderados e pessoas envolvidas.

Nesse estilo há a centralização do poder no líder, com enfoque nas tarefas e objetivos. Muitas vezes, não atendendo as opiniões e colaborações dos subordinados.

Seguindo este conceito Araújo afirma acerca do estilo autocrático ou autoritário: "o líder tem o comportamento regido pela tradição, não costumando ouvir e atender as reivindicações de seus seguidores. Esse estilo é adotado principalmente pelo sexo masculino nas organizações" (FRANÇA, 2019, p.57).

\subsection{Estilo democrático}

O estilo democrático é aquele que envolve mais os funcionários nas tomadas de decisões, ele delega autoridade com o intuito de promover a participação de maior parte dos envolvidos, o que o torna estilo com mais conjunto. No estilo democrático é possível opinar juntamente com o líder, sem que haja conflitos.

É um estilo que se interessa pelo ponto de vista do funcionário. Sobre o estilo democrático, Araújo defende que:

"No estilo democrático ou participativo ao contrário do estilo autocrático o enfoque são as relações humanas e não a produção. Por conta disso, os objetivos e estratégias são definidos tanto pelo líder, quanto pelos colaboradores, de maneira totalmente democrática, característica presente em líderes femininas" (FRANÇA, 2019, p 57).

\subsection{Estilo liberal ou laissez-faire}

O "estilo liberal" é aquele apresenta mais liberdade, como é representado em seu nome. O grupo geralmente tem sua liberdade de atuação e escolha 
concedida. Não há tanto o controle por parte do líder. Sendo considerado, muitas vezes, como um estilo onde não existe a supervisão do líder, e por isso sem avaliação ou regulação do mesmo no processo dos acontecimentos, ou seja, acontece a autonomia dos liderados na tomada de decisões para o enfrentamento das responsabilidades, com a criação própria de metas e planos. O líder só atuará quando for questionado e agirá de forma superficial

O estilo laissez-faire é conhecido como os chamados líderes de rédea solta, contudo está liberdade oferecida por essas pessoas pode passar a impressão de que a liderança não existe, pois, não há um foco como nos estilos democrático e autoritário. (FRANÇA, 2019, p.59).

De acordo com França (2019), o líder laissez-faire geralmente concede aos seus funcionários total liberdade para que tomem as decisões fazendo seu trabalho se realizado da melhor maneira que lhes convém e que achar correto. Na liderança do tipo liberal, ocorre a liberdade integral trazendo a decisão com menor interferência do líder e maior representação individual e do grupo.

\section{ANÁLISE DOS DADOS}

\section{Gráfico 1. Idade}

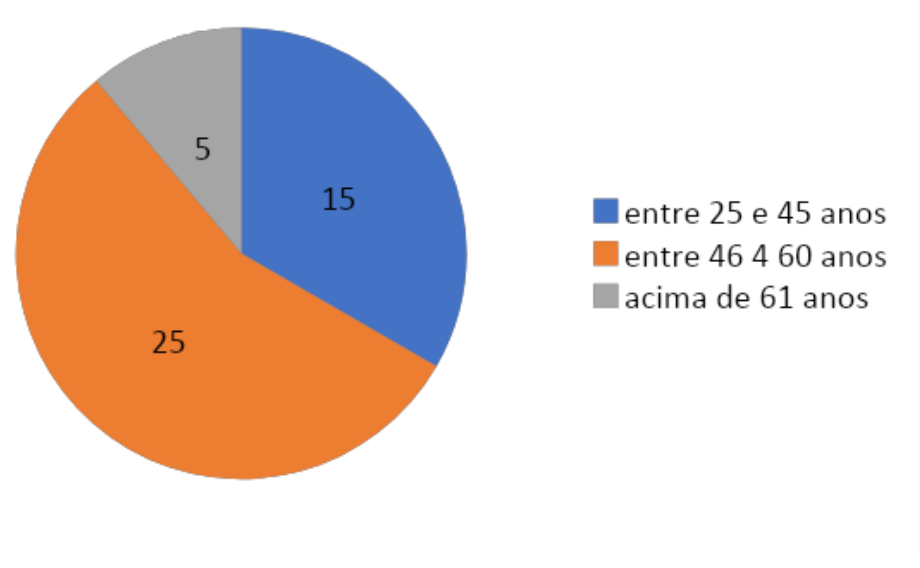

Fonte: Própria autora.

Os profissionais entrevistados possuem entre 25 até 65 anos de idade, foram escolhidos aleatoriamente. 
Gráfico 2. Sexo

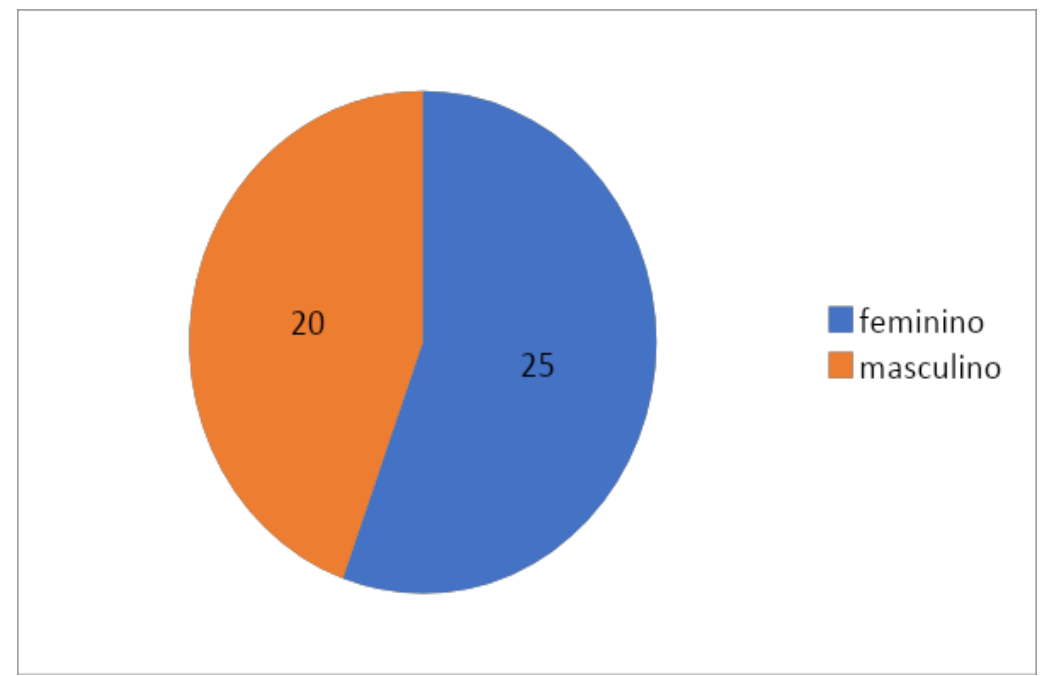

Fonte: Própria autora.

Foram entrevistados(as): 25 são do sexo feminino e 20 são do sexo masculino.

\section{Gráfico 3. Formação}

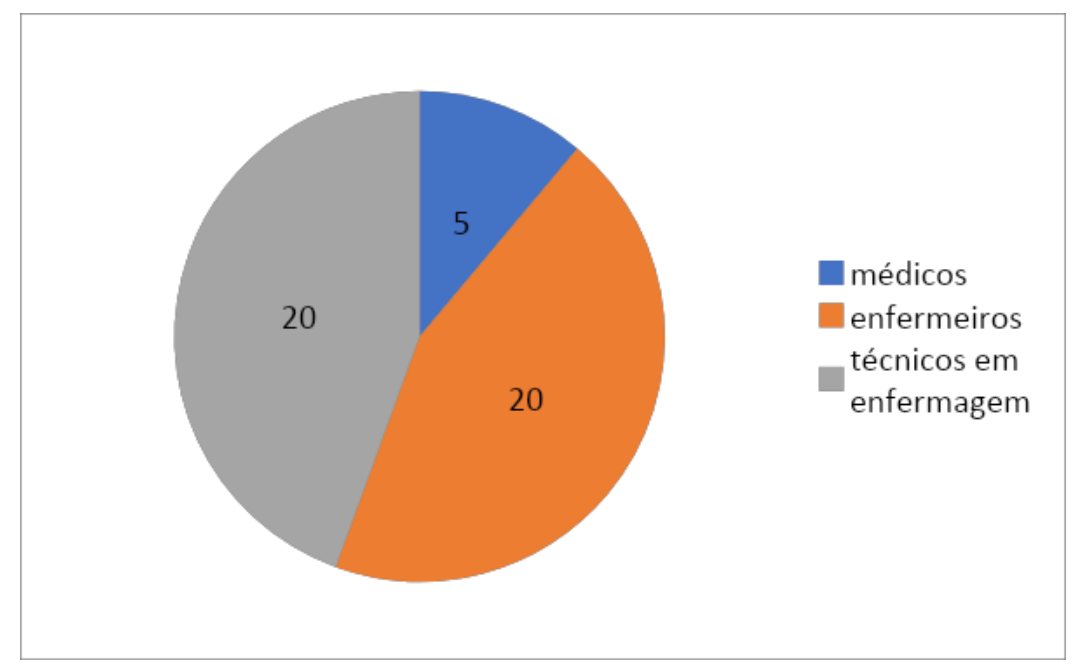

Fonte: Própria autora.

Foram entrevistados(as): 05 médicos, 20 enfermeiros e 20 técnicos de enfermagem. 
Gráfico 4. Tempo de exercício da profissão?

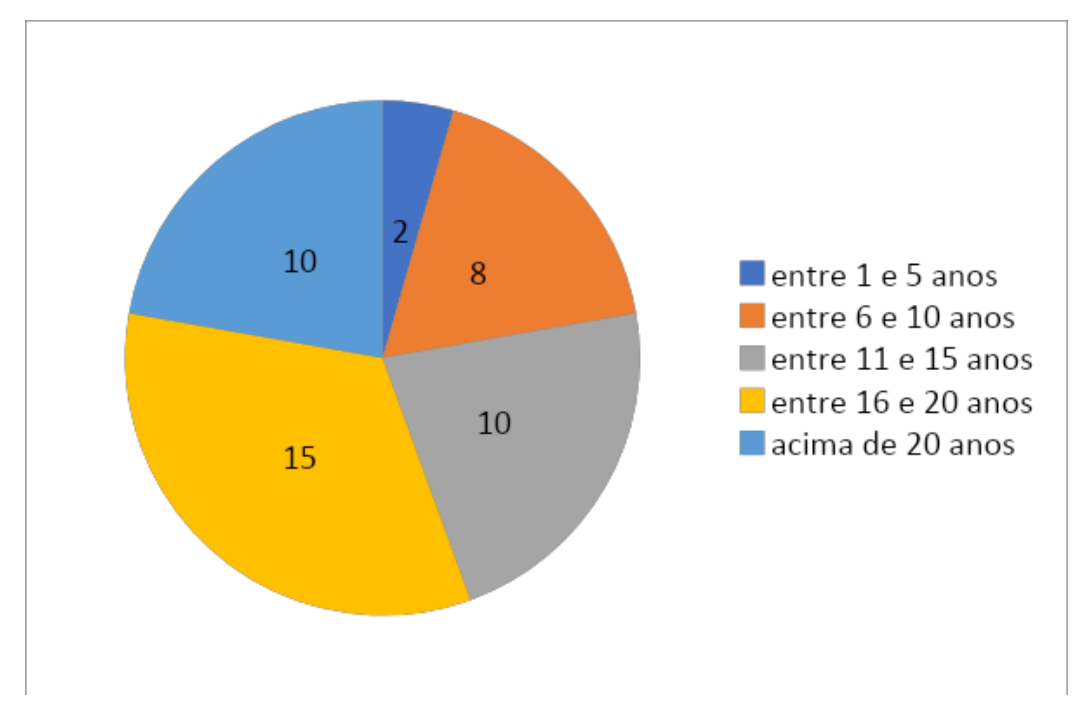

Fonte: Própria autora.

Dois deles exercem a profissão de saúde apenas 3 anos; oito deles exercem há 10 anos; 10 deles exercem há 14 anos; 15 deles exercem há 18 anos e os demais exercem mais de 25 anos.

Gráfico 5. Você gosta da função que exerce?

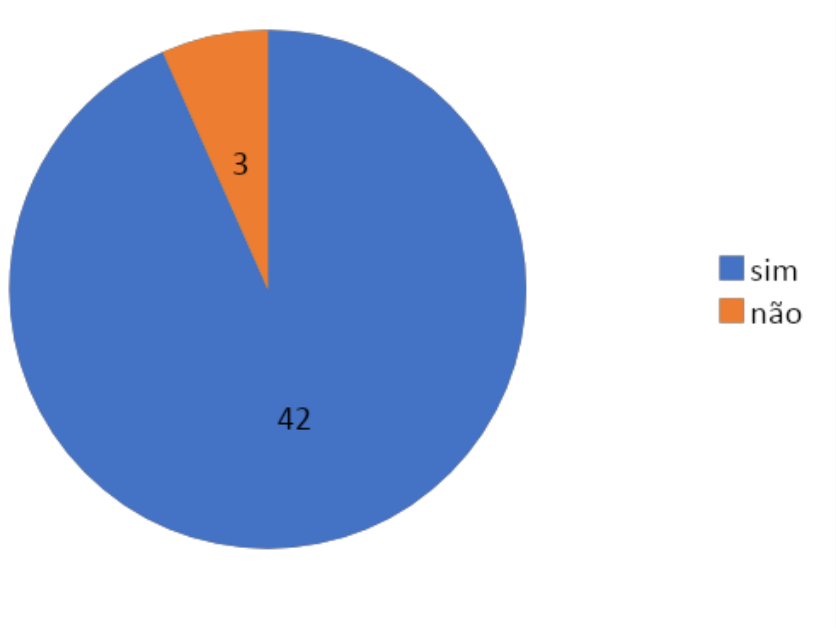

Fonte: Própria autora.

Durante a entrevista 42 pessoas entrevistadas responderam que gostam da função que exercem já 03 pessoas alegaram não gostar. 
Gráfico 6. Você se acha uma pessoa motivada dentro do trabalho

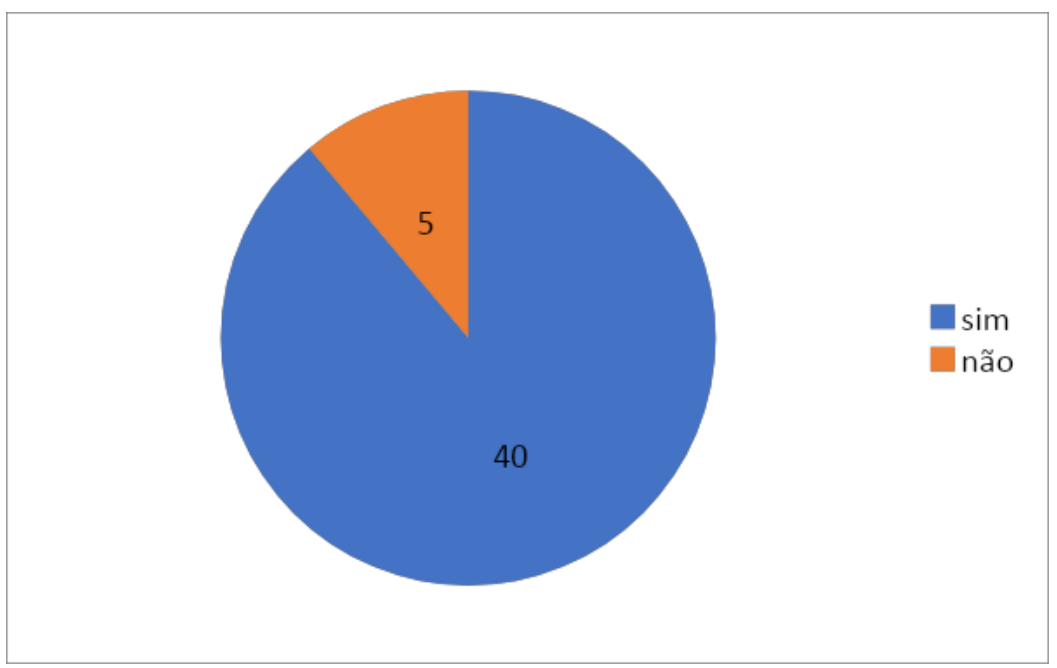

Fonte: Própria autora.

Durante a entrevista 40 entrevistados falaram que sim, são motivadas no trabalho, já 05 falaram que não.

Gráfico 7. Para você de onde vem a motivação para um bom desempenho laboral?

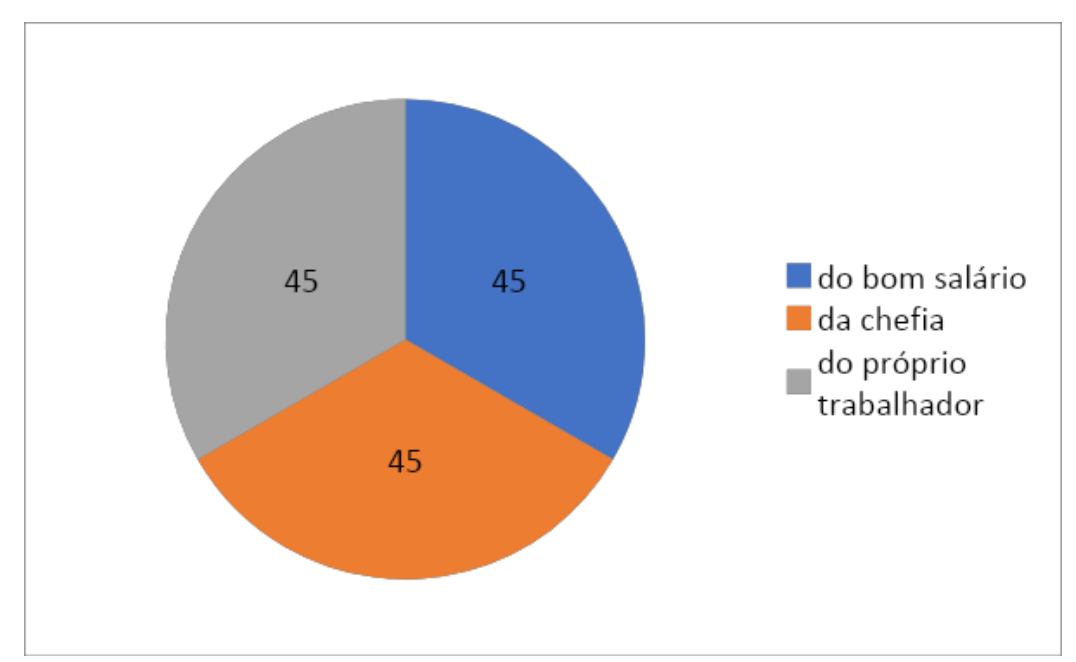

Fonte: Própria autora.

Durante a entrevista foi perguntado de onde vem a motivação no trabalho e 45 responderam: Bom salário, boa chefia e do próprio trabalhador. Com base nas respostas é de extrema importância estimular a motivação, em linhas gerais, eles são todas as ações e procedimentos necessários para garantir um ambiente favorável e estimulante para criar condições ideais de trabalho. 
Gráfico 8. Você já desenvolveu alguma doença emocional devido ao trabalho?

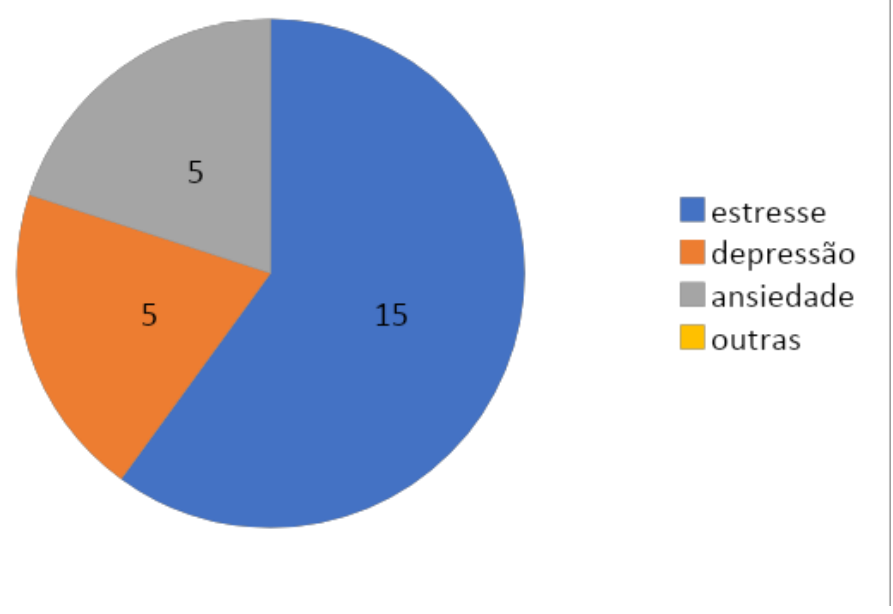

Fonte: Própria autora.

Durante a entrevista foi perguntado aos 45 funcionários se já desenvolveram alguma doença emocional devido as suas atividades laborais e as respostas foram: Dos 45 entrevistados 15 afirmam ter desenvolvido estresse patológico, 05 depressão ligado ao trabalho, 05 ansiedade patológica e 20 alegaram não ter desenvolvido nem uma doença emocional ligado ao trabalho.

Gráfico 9. A chefia do seu setor ajuda na motivação diária de seu trabalho?

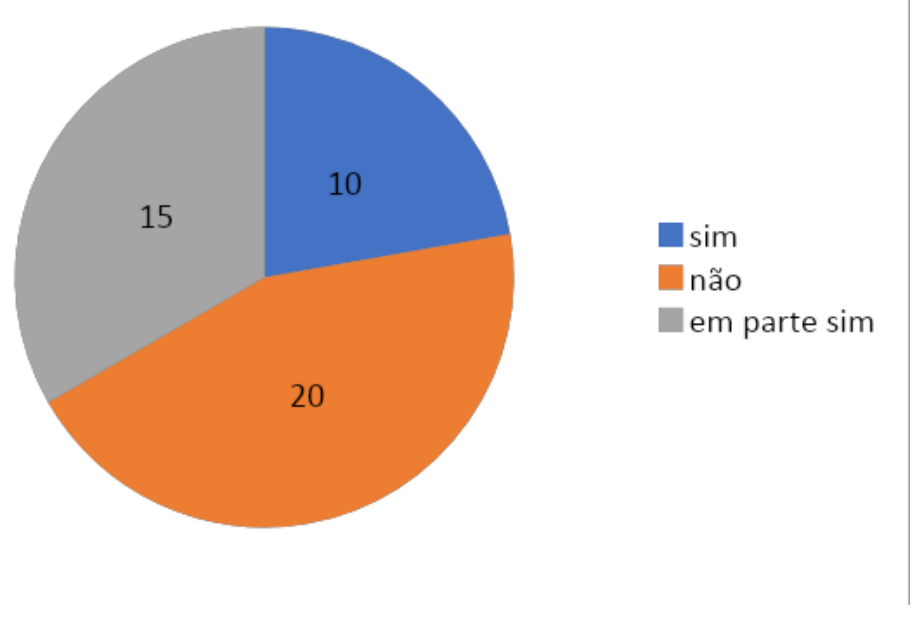

Fonte: Própria autora. 
$\mathrm{Na}$ entrevista foi perguntado se a chefia do setor auxilia na motivação dos trabalhadores e tivemos a resposta dos 45 trabalhadores: 10 que disseram que sim, 20 disseram que não ajudava e 15 disse que em parte sim. O papel da liderança na motivação é indiscutível. Um bom líder é capaz de enxergar as pessoas com empatia e agir de acordo com a necessidade de cada uma.

\section{CONCLUSÃO}

Para criação desse artigo estudamos a importância da educação permanente nas estratégias motivacionais no ambiente de trabalho, como também o reflexo da motivação dos trabalhadores na qualidade do serviço de saúde prestado ao cliente hospitalizado.

Nessa pesquisa foi visto que o ambiente de trabalho não deve ser estruturado apenas para o alcance de um único objetivo. Dentro deste acontecem relações com várias pessoas e estas precisam estar sempre entusiasmadas, encorajadas e motivadas para trabalhar de forma mais efetiva.

Para ter esses trabalhadores motivados é necessário entender as necessidades dos funcionários proporcionando meios para que eles adquiram conhecimentos, realizem melhor seus trabalhos aliados às ferramentas úteis da educação permanente oferecidas no seu ambiente de trabalho. Os funcionários motivados se tornam mais produtivos, ajudando e incentivando os colegas a se motivarem também.

Segundo Vilela (2015) diz que motivar um funcionário não é apenas aumentar seu salário. As técnicas motivacionais são aplicadas em demandas simples, sendo utilizadas desde um curso de aperfeiçoamento até mesmo nas oportunidades de crescimento profissional.

É sabido que a motivação no ambiente labora é o elemento propulsor e incentivador do desempenho do ser humano. É impulsionado através das necessidades, dos sonhos pessoais, das ideias entre outras construídas pela própria caraterística do sujeito.

A educação permanente em um ambiente de trabalho tem um proposito 
superior a simples técnica de atualizar os funcionários para melhorias de suas atividades laborais, possui o poder de motivar os funcionários fazendo enxergar um futuro maior para vida deles.

\section{REFERÊNCIAS}

ALMEIDA. J. R. S; D. O.B; K. G. H. S; Educação Permanente em Saúde: uma estratégia para refletir sobre o processo de trabalho. Revista da ABENO. 16 (2): 7-15, 2016.

BARROS, F. C: Motivação e satisfação no trabalho dos servidores técnicos administrativos em educação. [manuscrito], 2015. $177 \mathrm{f}$.

BLANCHARD, K; CAREW, D; CAREW, E. P. O gerente minuto desenvolve equipes de alto desempenho. Rio de Janeiro: Record, 2016.

FRANÇA.W. M: Estratégias motivacionais no ambiente de trabalho: ações educativas para um bom desempenho laboral. Dissertação do mestrado em ciências da educação pela Facultad Interamericana de Ciencias SocialesAssunção-PY (2019).

LEITE. C. E; MARINHO. C. J. M; SILVA. C.J; DECHANDT. S.G: A motivação no ambiente de trabalho: um estudo de caso na feira dos importados. Trabalho apresentado no XII - Congresso nacional de excelência em gestão \& III Inovarse Responsabilidade social aplicada-SET/2016.

LUIZ.D. S; BERTONI. F. A; MACHADO. G. B: Análise do grau de motivação comparando os fatores expostos por herzberg: Estudo de caso em uma empresa de formação de condutores. Artigo publicado pela Rev. RECAPE. Vol. 9 | № 1 | Ano 2019 Páginas 28-45. 
MAXIMIANO, Antonio Cesar Amaru. Introdução à Administração. 5. ed. São Paulo: Atlas. 2000.

MASUMOTO.L.K; F.C.J: Saúde mental e trabalho: um levantamento da literatura nacional nas bases de dados em Psicologia da Biblioteca Virtual de Saúde. (BVS). Artigo. Saúde, Ética \& Justiça. 2015;19(1);1-11.

MARTINEZ \& PARAGUAY: Satisfação e saúde no trabalho - aspectos conceituais e metodológicos. Cadernos de Psicologia Social do Trabalho, 2015, vol. 6, pp. 59-78.

MACHADO.A. S: O papel do líder na formação e desenvolvimento das equipes de alta performance. Trabalho de conclusão do curso de pósgraduação em MBA Gestão Financeira e Controladoria, da Universidade La Salle Unilasalle. Julho 2017.

MIRANDA. C: 0 desafio em manter funcionários motivados: os fatores motivacionais para o trabalho. Trabalho de conclusão do curso de pósgraduação em gestão de recursos humanos. Escola superior aberta do Brasil $\operatorname{ESAB}(2017)$.

SILVA. M. P; B.S.H; S.A: Relação entre saúde mental e trabalho: a concepção de sindicalistas e possíveis formas de enfrentamento. Rev Bras Saude Ocup 2016;41:e23.

PEREIRA.L. Á, Silva. K, Andrade. M. Benedito: Educação permanente em saúde: uma prática possível. Rev enferm UFPE on line., Recife, 12(5):146979, maio., 2018.

VILELA. A.V \& SALDANHA. M: A importância da motivação e sua influência no ambiente de trabalho. Trabalho de conclusão da PÓSGRADUAÇÃO "LATU-SENSO. UNIVERSIDADE CANDIDO MENDES - RJ (2015). 